\title{
Fahmy's four quadrant sutures: a new technique for control of blood loss during cesarean delivery for placenta previa
}

\author{
Mohamed S. Fahmy ${ }^{1}$, Laila Ezzat ${ }^{1}$, Maraey M. Khalil ${ }^{1}$, Ahmed H. Elsayed ${ }^{1}$, Sherif S. Fahmy ${ }^{1}$, \\ Adham Badawy ${ }^{1}$, Hossam Ramadan', Ahmed M. Abbas ${ }^{2 *}$
}

\section{${ }^{1}$ Department of Obstetrics and Gynecology, Faculty of Medicine, Aswan University, Egypt}

${ }^{2}$ Department of Obstetrics and Gynecology, Faculty of Medicine, Assiut University, Egypt

Received: 08 June 2018

Accepted: 03 July 2018

\section{*Correspondence:}

Dr. Ahmed M. Abbas,

E-mail: bmr90@hotmail.com

Copyright: () the author(s), publisher and licensee Medip Academy. This is an open-access article distributed under the terms of the Creative Commons Attribution Non-Commercial License, which permits unrestricted non-commercial use, distribution, and reproduction in any medium, provided the original work is properly cited.

\begin{abstract}
Background: The objective of this study is to assess the efficacy and safety of Fahmy's four quadrant suture technique (FFQS) in controlling blood loss during cesarean delivery for placenta previa (PP).

Methods: The study was carried out in a tertiary University Hospital between January 2017 to December 2017 involved 12 women with heavy bleeding occurred after removal of the placenta from the lower section during cesarean delivery for PP. The FFQS technique consisted of two sutures to ligate the uterine branches on both sides and two sutures on the anterior and posterior wall of the lower uterine segment. Details regarding the management and maternal outcomes were recorded.

Results: The mean age of the study participants was $29.58 \pm 5.29$ years and the mean parity was $2.25 \pm 1.14$. The mean gestational age at termination of pregnancy was $36.91 \pm 1.38$ weeks. The mean duration of the whole surgery was $78.75 \pm 43.28$ minutes, while the mean duration of FFQS technique was only $10 \pm 2.09$ minutes. The technique was exclusively effective in 8 out of 12 cases $(66.67 \%)$ while 2 cases needed bilateral internal iliac artery ligation and 2 cases needed hysterectomy. The mean amount of blood loss in all cases was $2433.33 \pm 833.76 \mathrm{ml}$. the mean amount of transfused packed RBCs was $3.92 \pm 1.68$ units and fresh frozen plasma (FFP) was $3.42 \pm 1.44$ units. All cases had uneventful postoperative course and no mortality cases in present series.

Conclusions: The new technique; FFQS represents a rapid, effective, and inexpensive opportunity for women with bleeding from the lower segment of uterus due to PP. This simple procedure should be attempted before other complex measures to achieve good hemostasis.
\end{abstract}

Keywords: Cesarean delivery, Placenta previa, Postpartum hemorrhage

\section{INTRODUCTION}

Enormous postpartum hemorrhage (PPH) is a serious complication of labor. It is the chief reason of maternal mortality and morbidity for both the developing and developed world. ${ }^{1,2}$ Placental abnormalities are a major contributor to obstetric hemorrhage. ${ }^{3}$ However, hemostasis regarding placenta previa (PP) is extremely challenging owing to the reduced contractility of the uterine lower segment. ${ }^{4}$ Since the introduction of uterine compression suture by B-Lynch, numerous techniques have been advocated, a number of different sutures were establishing to be effective in controlling $\mathrm{PPH}$ as Hayman, Cho and Khairy's sutures. ${ }^{5-9}$ They have showed to be competent and safe choices to hysterectomy. ${ }^{10}$ Additionally, tamponade using balloon maneuvers have been recognized as an efficient adjuvant policy for attaining hemostasis in enormous PPH caused by uterine atony. ${ }^{11,12}$ 
There are numerous suture ways designed to control hemorrhage in the lower uterine segment throughout cesarean delivery (CD) for PP such as, Cho's hemostatic suturing technique, circular isthmic-cervical sutures, Transverse annular compression sutures, Antero posterior compressive suture of the lower uterine segment, multiple 8 figure sutures. ${ }^{7,13-16}$ Until now, there is no agreement concerning the advantage of certain procedure to another in serious PPH and currently, there's no gold-standard surgical method for this problem because each one of the existing methods has pros and cons. The constraints are reliant on the accessibility and expertise of surgeons, services, and local strategies. ${ }^{17}$ However, in many patients, simply hemorrhage happens from lower segment and the usage of an easy suture is anticipated to be simpler to perform. Authors supposed a new simple conservative technique "Fahmy's four quadrant sutures (FFQS)" for control of lower segment bleeding after placental removal in cases of PP. Therefore, the aim of present study was to assess the efficacy and safety of FFQS technique in controlling blood loss from placenta previa during $\mathrm{CD}$.

\section{METHODS}

This study was carried out from January 2017 to December 2017 in present Obstetrics and Gynecology department of Aswan University Hospital, a teaching tertiary care referral hospital in Upper Egypt. An approval was obtained by the Ethical Review Committee of Aswan University Hospital.

In present study, 12 patients presented by profuse bleeding from placental bed during CD were included. Women were included in this study if bleeding occurred after placental removal from the lower segment while the rest of the uterus is well contracted with no hemorrhage.

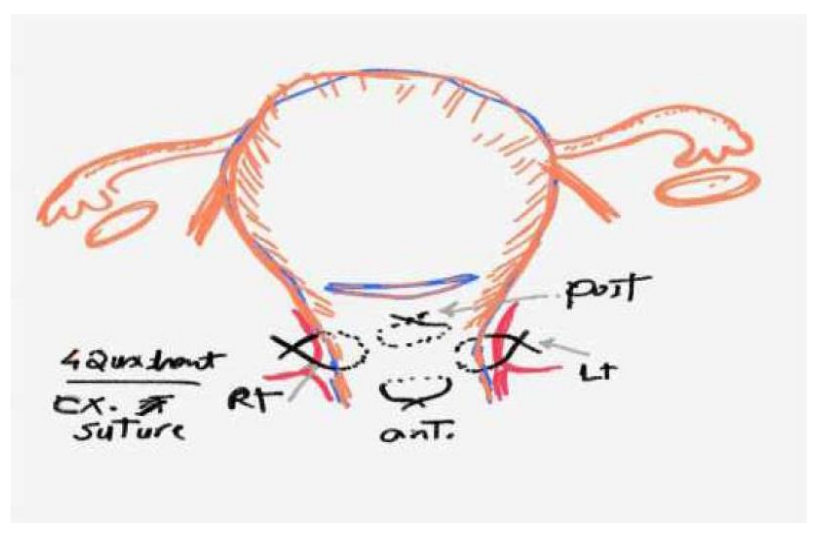

Figure 1: Diagram demonstrates the place of Fahmy's four quadrant sutures.

The FFQS technique consisted of two sutures to ligate the uterine branches on both sides and two sutures on the anterior and posterior wall of the lower uterine segment was performed in eligible women (Figure 1) according to the following steps:
The uterus was exteriorized. After dissecting off the bladder downward as low as possible, the assistant carried the uterus and pushed it laterally to expose the left broad ligament. Four sutures are taken in the lower uterine segment, all of them at a level $1-3 \mathrm{~cm}$ below the cesarean incision. The first; on the left lateral edge of the lower uterine segment to ligate the branches of the left uterine artery. The second; on the right lateral edge of the lower uterine segment to ligate the branches of the right uterine artery. The third; on the anterior wall of the lower uterine segment just above the bladder reflection with the index finger of the left hand inside the lower uterine segment to assess the patency of the cervical opening (to prevent occlusion of the cervical canal by the suture) (Figure 2).

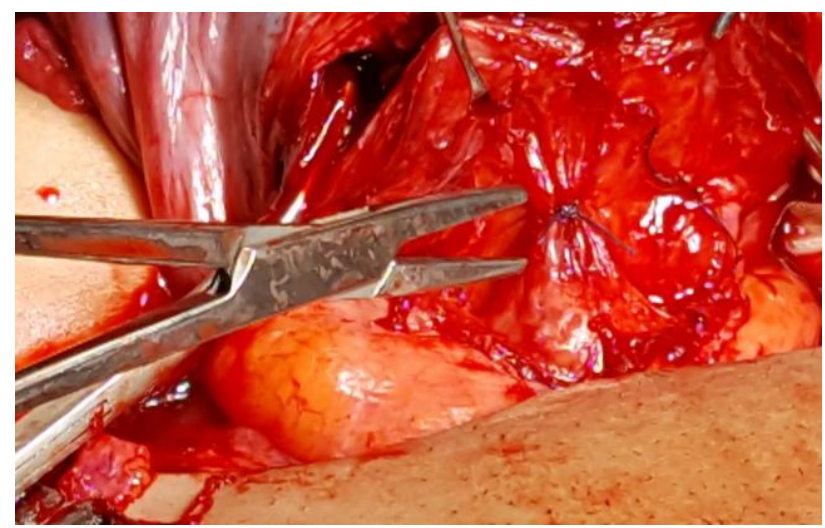

Figure 2: Intraoperative view of the anteriorly placed suture in the lower uterine segment.

The two terminates of the thread were tied over the anterior surface as tightly as possible, care was taken to avoid damaging the bladder. The fourth suture; on the posterior wall of the lower uterine segment, while the assistant carried the uterus and pushed it anteriorly to expose posterior uterine wall. The needle was permitted to totally pass in the whole thickness of the wall to enter the uterine cavity. The two terminates of the thread were tied over the posterior wall as tightly as possible (Figure 3 ). Care was taken not to injure the bowel and the ureters.

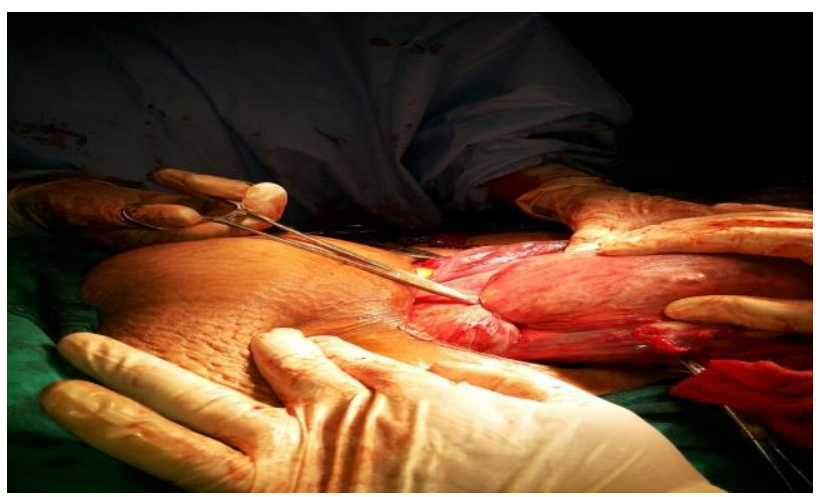

Figure 3: Intraoperative view of the posteriorly placed suture in the lower uterine segment. 
The vagina was checked to ensure that the bleeding is controlled. If the bleeding did not stop, the procedure was then repeated on a level lower than the 1st one. The number of sutures necessary was determined by the measurements of the lower uterine segment and the insistence of bleeding. The uterine incision was closed in the standard technique, in two layers; but the peritoneum of lower uterine segment was not closed. The chief outcomes were the amount of intraoperative blood loss, the need for additional uterotonics, the need for blood transfusion, the need of relaparotomy or hysterectomy to stop hemorrhage, and the associated complications. Intraoperative blood loss was measured by adding the volume of the contents of the suction bottle and the difference in weight (in grams) between the dry and the soaked operation sheets and towels $(1$ gram $=1 \mathrm{ml})$.

A dose of $1 \mathrm{~g}$ of first-generation cephalosporin (Cefazolin®; Bristol Mayers Squibb, Cairo, Egypt) was administered intravenously every 12 hours for 3 days. All patients were discharged after at least 5 days of hospital stay.

\section{RESULTS}

Within this study period, there were twelve patients included in this study. The characteristics of these patients are presented in Table 1.

Table 1: The characteristics and outcomes of the patients.

\begin{tabular}{|c|c|c|c|c|c|c|c|c|c|c|}
\hline $\begin{array}{l}\text { Case } \\
\text { no. }\end{array}$ & $\begin{array}{l}\text { Maternal } \\
\text { age } \\
\text { (years) }\end{array}$ & Parity & $\begin{array}{l}\text { Gestational } \\
\text { age } \\
\text { (weeks) }\end{array}$ & $\begin{array}{l}\text { Previous } \\
\text { CD }\end{array}$ & $\begin{array}{l}\text { Duration } \\
\text { of surgery } \\
\text { (minutes) }\end{array}$ & $\begin{array}{l}\text { Duration } \\
\text { of FFQS } \\
\text { (minutes) }\end{array}$ & $\begin{array}{l}\text { Additional } \\
\text { surgical } \\
\text { procedure }\end{array}$ & $\begin{array}{l}\text { Estimated } \\
\text { blood loss }\end{array}$ & $\begin{array}{l}\text { Blood } \\
\text { transfusion }\end{array}$ & $\begin{array}{l}\text { Duration of } \\
\text { hospital } \\
\text { stay (days) }\end{array}$ \\
\hline 1 & 33 & 3 & 37 & 3 & 120 & 12 & BIIAL & 3500 & $\begin{array}{l}6 \text { units } \\
\text { PRBCs } \\
4 \text { units FFP }\end{array}$ & 4 \\
\hline 2 & 28 & 4 & 36 & 4 & 145 & 14 & Hysterectomy & 3000 & $\begin{array}{l}4 \text { units } \\
\text { PRBCs } \\
4 \text { units FFP }\end{array}$ & 6 \\
\hline 3 & 35 & 3 & 37 & 2 & 45 & 10 & - & 2000 & $\begin{array}{l}4 \text { units } \\
\text { PRBCs } \\
3 \text { units FFP }\end{array}$ & 4 \\
\hline 4 & 28 & 2 & 35 & 2 & 45 & 10 & - & 2500 & $\begin{array}{l}4 \text { units } \\
\text { PRBCs } \\
4 \text { units FFP }\end{array}$ & 5 \\
\hline 5 & 29 & 1 & 39 & 1 & 60 & 8 & - & 3000 & $\begin{array}{l}5 \text { units } \\
\text { PRBCs } \\
3 \text { units FFP }\end{array}$ & 5 \\
\hline 6 & 30 & 1 & 39 & 0 & 50 & 8 & BIIAL & 3500 & $\begin{array}{l}6 \text { units } \\
\text { PRBCs } \\
6 \text { units FFP }\end{array}$ & 6 \\
\hline 7 & 25 & 1 & 35 & 1 & 50 & 10 & - & 1500 & $\begin{array}{l}2 \text { units } \\
\text { PRBCs } \\
2 \text { units FFP }\end{array}$ & 4 \\
\hline 8 & 21 & 1 & 36 & 1 & 50 & 12 & - & 1800 & $\begin{array}{l}3 \text { units } \\
\text { PRBCs } \\
2 \text { units FFP }\end{array}$ & 4 \\
\hline 9 & 39 & 3 & 37 & 3 & 45 & 8 & - & 1500 & $\begin{array}{l}2 \text { units } \\
\text { PRBCs } \\
2 \text { units FFP }\end{array}$ & 5 \\
\hline 10 & 24 & 2 & 38 & 2 & 130 & 8 & - & 2000 & $\begin{array}{l}4 \text { units } \\
\text { PRBCs } \\
3 \text { units FFP }\end{array}$ & 5 \\
\hline 11 & 36 & 4 & 36 & 4 & 150 & 12 & Hysterectomy & 3500 & $\begin{array}{l}6 \text { units } \\
\text { PRBCs } \\
6 \text { units FFP }\end{array}$ & 7 \\
\hline 12 & 27 & 2 & 38 & 2 & 55 & 8 & - & 1400 & $\begin{array}{l}1 \text { units } \\
\text { PRBCs } \\
2 \text { units FFP }\end{array}$ & 3 \\
\hline
\end{tabular}

The mean age of the study participants was $29.58 \pm 5.29$ years and the mean parity was $2.25 \pm 1.14$. The mean gestational age at termination of pregnancy was $36.91 \pm 1.38$ weeks. The mean number of previous CDs was $2.08 \pm 1.24$. The mean duration of the whole surgery was $78.75 \pm 43.28$ minutes, while the mean duration of FFQS technique was only $10 \pm 2.09$ minutes. The technique was exclusively effective in 8 out of 12 cases $(66.67 \%)$. On the other hand, two cases needed complementary bilateral internal iliac artery ligation (BIIAL) and the last 2 cases hysterectomy was performed due to marked atony and persistence of severe intraoperative bleeding. 
The mean amount of blood loss in all cases was $2433.33 \pm 833.76 \mathrm{ml}$. the mean amount of transfused packed RBCs was $3.92 \pm 1.68$ units and fresh frozen plasma (FFP) was $3.42 \pm 1.44$ units.

The mean duration of hospital stay was $4.83 \pm 1.11$ days. All cases had uneventful postoperative course and no mortality cases in present series.

\section{DISCUSSION}

The concept of compression has long been utilized for controlling severe uterine hemorrhage. ${ }^{18}$ With the progressing number of caesarean section and the emerging characteristic of almost all $\mathrm{PPH}$, there is a continuous necessity for efficient intervention. The advancements for the conservative treatment concerning these serious circumstances in the last decade entail the creation of the B-Lynch stitch and its variations. ${ }^{19}$ In present series, a new conservative management technique FFQS was evaluated which is simply consisted of four sutures applied to the lower uterine segment to control the arterial supply of this difficult anatomical area and minimize PPH. The total success rate of FFQS solely as a first line was $(8 / 12,66.7 \%)$ and if combined with BIIAL was $(10 / 12,83.3 \%)$ to prevent hysterectomy.

Different types of uterine tamponade, from sterile roller gauze to multiple balloon catheters have been recognized as a competent adjuvant approach for getting hemostasis in enormous PPH. The Bakri balloon is the least invasive, fast way in the controlling of bleeding caused by placenta previa with negligible complications. ${ }^{18}$ However, compared to the balloon catheters, FQCS is easier, rapid, with less infection and without the susceptibility to slipping or rupture. Application of local hemostatic agent, hemostatic fleece, hemostatic gel directly on the bleeding surfaces of the lower uterine segment has been used to achieve hemostasis during cesarean section produced by placenta previa, it provides rapid and active hemostasis in the lower segment, where surgical interference may be problematic, although quick and effective are not suitable in various cases especially placenta previa accreta and these agents are not permanently obtainable in developing countries. ${ }^{20,21}$

Most of the compression sutures such as B-Lynch, Hayman and Cho square designed for atonic PPH and cannot prevent hemorrhage within the lower uterine segment all the time. However, several specific stitches were established to stop bleeding in this challenging anatomical area, such as Transverse annular compression sutures, antero posterior compressive suture of the lower uterine segment, multiple 8 sutures are informed to be effective in controlling severe PPH from the lower uterine segment with a varying degree of success. ${ }^{14-16}$ Mitwaly and his colleague tried a new method of combined surgical steps in management of PA. ${ }^{22}$ It was successful in 18 out of 20 cases for conservation of the uterus with no postpartum hemorrhage or maternal mortality. However, the FFQS is possible to be more rapid and to some extent effective.

Several combinations of management are utilized for PPH, a Foley catheter balloon used to compress the bleeding site and an absorbable stitch was positioned to bandage the lower uterine segment to deliver additional compression above the balloon, combining sutures of BLynch with a modified Cho suture, the uterine sandwich joining the B-lynch suture plus an intrauterine gauze tampon, bilateral hypogastric arterial ligation, Bakri balloon tamponade and methotrexate therapy, B-Lynch brace suture technique with uterine artery embolization. ${ }^{17,23-26}$ However, these approaches are possibly useful if the bleeding in both the upper and lower segments of the uterus. However, services for interventional radiology do not always exist. Though, for several cases, just lower segment bleeding occurs and usage of simplified stitches like FFQS is probable to be easier to perform.

There are some difficulties in present technique which must be considered, first the presence of adhesions due to previous CDs which makes exteriorization of the uterus is not possible in every case also, and the bladders are subsequently difficult to move down, takes a long time in dissection which often might lead to more bleeding. Additionally, cases with placenta increta erodes the lower uterine segment and sometimes no anterior wall was existing. Use of the FFQS deal with the majority of cases of lower segment $\mathrm{PPH}$, when there is only restricted bleeding, but is not appropriate for cases of bleeding due to placenta previa accreta. Hemostasis by compression or a figure-of-eight suture is a superior option to manage these problems. Also, in presence of severe adhesions tamponade with multiple balloon devices is the best choice, the FFQS should not be used if there is continuous bleeding from the body of the uterus, or if the myometrium of the lower segment is very thin, transverse annular compression is more suitable in this case. For patients with placenta accreta, authors believe that peripartum hysterectomy is safer for the mothers.

\section{CONCLUSION}

To conclude, using the FFQS may possibly provide inexpensive, rapid, and efficient alternative for patients with uterine bleeding from the lower segment, particularly among those with PP and to certain extent, it can diminish the bleeding and improve consequences of the adherent placenta. Still, the outcomes of the current research need verification in a large number of cases. Furthermore, the effectiveness of the FFQS needs to be balanced with other techniques under different circumstances.

Funding: No funding sources

Conflict of interest: None declared

Ethical approval: The study was approved by the Institutional Ethics Committee 


\section{REFERENCES}

1. Devine PC, Wright JD. Obstetric hemorrhage. Introduction. Semin Perinatol. 2009;33(2):75.

2. Abbas AM, Amin MT, Ali SS, Salem NZ. Maternal mortality: a tertiary care hospital experience in Upper Egypt. Int J Reprod Contracept Obstet Gynecol. 2016;5(5):1466-71.

3. Fan D, Xia Q, Liu L, Wu S, Tian G, Wang W, et al. The incidence of postpartum hemorrhage in pregnant women with placenta previa: a systematic review and meta-analysis. PLoS One. 2017;12(1):e0170194.

4. Law LW, Chor CM, Leung TY. Use of hemostatic gel in postpartum hemorrhage due to placenta previa. Obstet Gynecol. 2010;116 Suppl 2:528-30.

5. B-Lynch C, Coker A, Lawal AH, Abu J, Cowen MJ. The B-Lynch surgical technique for the control of massive postpartum haemorrhage: an alternative to hysterectomy? Five cases reported. BJOG. 1997;104(3):372-5.

6. Hayman RG, Arulkumaran S, Steer PJ. Uterine compression sutures: surgical management of postpartum hemorrhage. Obstet Gynecol. 2002;99(3):502-6.

7. Cho JH, Jun HS, Lee CN. Hemostatic suturing technique for uterine bleeding during cesarean delivery. Obstet Gynecol. 2000;96(1):129-31.

8. Ali MK, Badee AY, Abbas AM, Shazly SA. A novel technique for modified B-Lynch suture for the control of atonic postpartum haemorrhage. Aust N Z J Obstet Gynaecol. 2013;53:94-7.

9. Abbas AM, Sheha AM, Ali MK, Khalaf M, Gamal E. Successful term delivery after Khairy's modified Blynch suture technique: first case report. Middle East Fertil Soc J. 2017;22(1):87-90.

10. Mallappa Saroja CS, Nankani A, El-Hamamy E. Uterine compression sutures, an update: review of efficacy, safety and complications of B-Lynch suture and other uterine compression techniques for postpartum haemorrhage. Arch Gynecol Obstet. 2010;281(4):581-8.

11. Gronvall M, Tikkanen M, Tallberg E, Paavonen J, Stefanovic V. Use of Bakri balloon tamponade in the treatment of postpartum hemorrhage: a series of 50 cases from a tertiary teaching hospital. Acta Obstet Gynecol Scand. 2013;92(4):433-8.

12. Ali MK, Abbas AM, Abdelbadee AY, Shazly SA, AbdelMagied AM. Use of Foley's catheter balloon tamponade to control placental site bleeding resulting from major placenta previa during cesarean section. Proc Obstet Gynecol. 2016;6(3):4.

13. Dedes I, Ziogas V. Circular isthmic-cervical sutures can be an alternative method to control peripartum haemorrhage during caesarean section for placenta praevia accreta. Arch Gynecol Obstet. 2008;278(6):555-7.

14. Ying $H$, Duan $T$, Bao YR, Song YH, Wang DF. Transverse annular compression sutures in the lower uterine segment to control postpartum hemorrhage at cesarean delivery for complete placenta previa. Int $\mathrm{J}$ Gynaecol Obstet. 2010;108(3):247-8.
15. Penotti M, Vercellini P, Bolis G, Fedele L. Compressive suture of the lower uterine segment for the treatment of postpartum hemorrhage due to complete placenta previa: a preliminary study. Gynecol Obstet Investigation. 2012;73(4):314-20.

16. Shazly SA, Badee AY, Ali MK. The use of multiple 8 compression suturing as a novel procedure to preserve fertility in patients with placenta accreta: case series. The A N Z J Obstet Gynaecol. 2012; 52(4):395-9.

17. Zhu L, Zhang Z, Wang H, Zhao J, He X, Lu J. A modified suture technique for hemorrhage during cesarean delivery complicated by complete placenta previa. Int J Gynaecol Obstet. 2015;129(1):26-9.

18. Kumru P, Demirci O, Erdogdu E, Arisoy R, Ertekin AA, Tugrul S, et al. The Bakri balloon for the management of postpartum hemorrhage in cases with placenta previa. European J Obstet Gynecol Reprod Biol. 2013;167(2):167-70.

19. Zheng J, Xiong X, Ma Q, Zhang X, Li M. A new uterine compression suture for postpartum haemorrhage with atony. BJOG. 2011;118(3):370-4.

20. Portilla D, Hernandez-Giraldo C, Moreno B, Quijano F, Hoyos LR, Angarita AM, et al. A local hemostatic agent for the management of postpartum hemorrhage due to placenta previa and placenta accreta: a crosssectional study. Arch Gynecol Obstet. 2013;288(3):5439.

21. Fuglsang K, Dueholm M, Staehr-Hansen E, Petersen LK. Uterine healing after therapeutic intrauterine administration of Tacho Sil (hemostatic fleece) in cesarean section with postpartum hemorrhage caused by placenta previa. J Pregnancy. 2012;2012:635683.

22. Mitwaly AA, Abbas AM. Sequential surgical steps for conservative management of morbidly adherent placenta: case series, Thai J Obstet Gynecol. 2016;24:136-40.

23. Xiao JP, Zhang B. Combination of B-lynch and modified Cho sutures for postpartum hemorrhage caused by low-lying placenta and placenta accreta. Clinic Exp Obstet Gynecol. 2011;38(3):274-5.

24. Kaplanoglu M. The uterine sandwich method for placenta previa accreta in mullerian anomaly: combining the B-lynch compression suture and an intrauterine gauze tampon. Case Reports Obstet Gynecol. 2013;2013:236069.

25. Karateke A, Kucukbas M, Sozen H, Namazov A, Cakir S, Akdemir Y. Fertility sparing surgery on placenta invasion anomalies and placenta previa. Iranian $\mathrm{J}$ Reprod Med. 2012;10(3):271-4.

26. Koyama E, Naruse K, Shigetomi H, Sado T, Oi H, Kobayashi H. Combination of B-Lynch brace suture and uterine artery embolization for atonic bleeding after cesarean section in a patient with placenta previa accreta. J Obstet Gynaecol Res. 2012;38(1):345-8.

Cite this article as: Fahmy MS, Ezzat L, Khalil MM, Elsayed AH, Fahmy SS, Badawy A, et al. Fahmy's four quadrant sutures: a new technique for control of blood loss during cesarean delivery for placenta previa. Int J Reprod Contracept Obstet Gynecol 2018;7:3004-8. 